\title{
Relacionamentos puros no tempo de antigamente: curso da vida e condutas homossexuais no Pantanal-MS
}

\author{
Guilherme Rodrigues Passamani \\ Professor de Ciências Sociais/ UFMS
}

Resumo: Esse artigo é parte de uma pesquisa maior, que desenvolvi durante o doutorado sobre a intersecção entre envelhecimento, memória e condutas homossexuais na região do Pantanal de Mato Grosso do Sul, nas cidades de Corumbá (108 mil habitantes) e Ladário (21 mil habitantes). Procuro aqui, em um primeiro momento, destacar as mudanças e perspectivas observadas no âmbito da sexualidade entre meus interlocutores a partir de suas lembranças. E, em um segundo momento, problematizo a forma como se estruturavam os relacionamentos puros no chamado tempo de antigamente entre os interlocutores e os homens-homens.

Palavras-chave: curso da vida, condutas homossexuais, envelhecimento, Pantanal, sexualidade 


\title{
"True relationships" in the "old times": life course and homosexual behavior in Pantanal-MS
}

\begin{abstract}
This article is part of my $\mathrm{PhD}$ research about the intersection among aging, memory and homosexual behavior in Pantanal region of the state of Mato Grosso do Sul, Brazil, in the cities of Corumbá (108 thousand inhabitants) and Ladário (21 thousand inhabitants). Here, at first, I intend to highlight the changes and perspectives on the sphere of sexuality among my interlocutors based on their memories. Then, I discuss the way the true relationships were structured in the so called old times among my interlocutors and the true men.
\end{abstract}

Keywords: life-course, homosexual behavior, aging, Pantanal, sexuality.

\section{Relaciones puras en tiempo de antiguamente: curso de la vida y conductas homosexuales en el Pantanal-MS}

Resúmen: Este artículo forma parte de una investigación más grande, que he desarrollado durante el doctorado sobre la intersección entre envejecimiento, memoria y conductas homosexuales en la región del Pantanal de Mato Grosso do Sul, Brasil, en las ciudades de Corumbá (108 mil habitantes) y Ladário (21 mil habitantes). Busco inicialmente poner de relieve los cambios y perspectivas observados en el ámbito de la sexualidad, por algunos de mis interlocutores. Luego paso a plantear la forma cómo se han estructurado las relaciones puras en el dicho tiempo de antiguamente entre los interlocutores y los hombre-hombres.

Palabras clave: curso de la vida, conductas homosexuales, envejecimiento, Pantanal, sexualidad. 


\section{Introdução}

Esse artigo reflete parte das pesquisas que desenvolvi em meu trabalho de doutorado em Ciências Sociais no Instituto de Filosofia e Ciências Humanas da Unicamp. Minha tese versa sobre a intersecção entre envelhecimento, memória e condutas homossexuais ${ }^{1}$ na região do Pantanal de Mato Grosso do Sul, nas cidades de Corumbá (108 mil habitantes) e Ladário (21 mil habitantes). Realizei trabalho de campo entre julho de 2012 e fevereiro de 2014. Durante a pesquisa etnográfica, estabeleci contato com 17 pessoas com condutas homossexuais (homens e mulheres) e travestis, maiores de 50 anos, residentes nas duas cidades. O objetivo foi problematizar trajetórias, curso da vida e possíveis idiossincrasias da experiência desses sujeitos em regiões que não são caracterizadas como grandes centros urbanos.

$O$ processo de entrada em campo e contato com os potenciais interlocutores se deu a partir de diferentes abordagens. Em um primeiro momento, foram estabelecidos contatos com ONGs da cidade. Elas, por meio de redes pessoais, facilitaram minha inserção entre potenciais contatos. Vali-me também, da rede que estabeleci com servidores da UFMS no campus do Pantanal. Além disso, utilizei a internet como uma porta de entrada, acessando contatos por meio das salas de chat.

A região do Pantanal, onde estão as cidades de Corumbá e Ladário, é considerada uma das maiores extensões úmidas contínuas do Planeta (138.183 $\mathrm{km}^{2}$ ). Ela se demora por boa parte do centro da América do Sul, nos territórios do Brasil e da Bolívia. Corumbá recebeu um número grande de imigrantes de diferentes lugares do Brasil e do mundo. Certo ar cosmopolita, ainda que se trate de uma pequena cidade, tem suas raízes em seus antecedentes históricos (Corrêa e Corrêa, 2013).

Do ponto de vista econômico, o comércio facilitado pelo Porto da cidade, bem como as fazendas de gado no Pantanal e, posteriormente, a exploração dos minérios na região, foram seus alavancadores econômicos. Hoje Corumbá é uma cidade que conta com mais de 108 mil habitantes e tem sua economia fortemente ligada à exploração de minério, à pecuária, ao turismo, ao comércio e aos serviços de maneira geral.

A outra cidade, Ladário, é hoje uma cidade de pouco mais de 20 mil habitantes. Tem sua história muito ligada a Corumbá. De maneira geral, informalmente, pensa-se Corumbá e Ladário como uma continuação, uma vez que as cidades estão distantes apenas 6 quilômetros. A importância da cidade de Ladário está muito associada à presença do Sexto Distrito Naval da Marinha do Brasil.

1 Utilizo a expressão “condutas homossexuais" para me referir aos sujeitos com os quais eu estou trabalhando. Este é apenas um recurso para tentar aproximar uma série de categorias muito dispersas entre si e tratá-las em seus próprios termos. Utilizo esse recurso, pois estou lidando com informações acionadas por meio da memória e que falam, algumas vezes, de tempos que não são o presente e o que me é contado carrega uma fluidez grande entre o que atualmente compreendemos como orientação sexual e identidade de gênero. Ao falar em condutas homossexuais, estou fazendo uma referência às pesquisas de John Gagnon (2006). Para ele, as condutas sexuais seriam atos que exigiriam desenvolvimento da criatividade, amparadas por aspectos culturais mais amplos, fantasias individuais e códigos que permitiriam algum grau de interação social. Segundo Gagnon, a partir de sua crítica à "natureza" social dos comportamentos humanos, ele conseguiu explicar a importância e relevância da discussão sobre condutas sexuais. A explicação de Gagnon seguia o seguinte raciocínio: se todo o comportamento humano é social, não há possibilidade de existir um comportamento sexual biologicamente nu, mas sim uma conduta sexual socialmente vestida. 
A relevância da pesquisa está para além de se realizar em um lugar distante de um grande centro urbano. Não percebo que ela se justifique, meramente, por não estar na capital do estado, Campo Grande (com seus mais de 800 ooo habitantes). Em que pesem essas questões anteriores, o fato a ser destacado é justamente tentar olhar as condutas homossexuais de sujeitos que não migraram e construíram vivências possíveis para suas condutas, bem como desenvolveram estratégias de gestão de visibilidade na região.

Tento, aqui, mostrar potencialidades de cidades menores. Espaços em que podem emergir outras noções de centralidades e periferias. Quer dizer, no próprio Pantanal podem existir condições que permitam articular essas possíveis diferenças que constroem outros lugares de pertencimento. $\mathrm{O}$ ponto nodal da diferença, me parece, é como se estruturam as sociabilidades, bem como a produção de identidades, ainda que sejam fluidas, em um contexto específico.

Essa percepção é facilitada em vista de que os sujeitos da investigação permanecerem na cidade de origem. Tal questão pode representar uma relação mais tensa com certa ideia de anonimato e impessoalidade. Isso poderia levar os sujeitos a estabelecerem potenciais confrarias (Soliva, 2012) em que o segredo e o anonimato (Passamani, 2011) possam ter especiais importâncias.

Nesse particular, advirto, porém, que não tenho a intenção de problematizar "homossexualidade e envelhecimento no interior do Brasil". Entre outras razões, porque o Brasil é bastante plural e diverso e a noção de interior é, extremamente, complexa. Busco, no entanto, refletir sobre um interior específico e as experiências de envelhecimento de sujeitos com condutas homossexuais no local.

Corumbá e Ladário são cidades que ocupam posições estratégicas. Elas, estão na fronteira com a Bolívia. Além disso, há contingentes das Forças Armadas, quer dizer, são cidades de desterritorializações. Há um fluxo de homens, de corpos masculinos desterritorializados, e, quem sabe, este seja mais um fator a particularizar a experiência da "homossexualidade" na região. Em vista disso, resulta impossível a tentativa do Pantanal vocalizar o interior do Brasil, porque ali é um interior de fronteira, de cruzamentos e de migração.

Os trânsitos, fluxos e circulações de Corumbá e Ladário estão, geralmente, relacionados ao mundo do trabalho e ao turismo. Corumbá, por exemplo, é reconhecida em Mato Grosso do Sul como uma "cidade alegre" e festiva. Esta referência foi conquistada a partir das diversas festas, como o carnaval e as dos santos populares, mas também devido aos festivais culturais, musicais, além do turismo ecológico, sem contar no fator de ser rota para o turismo rumo aos andes peruanos.

Cabe ainda esclarecer que a alteridade de Corumbá e Ladário não é a Bolívia, país com o qual a região faz fronteira. A ligação é muito mais umbilical com o Rio de Janeiro. Isso se expressa, por exemplo, na estátua do Cristo Rei, em ritmos como samba e funk, festas como o carnaval, bem como certa leveza e bom-humor que seriam traços deixados por muitos cariocas da Marinha. Aliás, a Marinha seria outro traço marcante dessa alteridade.

Atentemos para um fator. Certa percepção desse "Pantanal urbano" de muita circulação deve ser observada com cautela. Os "inchaços" são pontuais. Como as cheias do Pantanal, ainda que duradouras, há os períodos de refluxos, em que são percebidos, outras vez, os traços da cidade provinciana, como relatam os interlocutores. Algumas características destacadas são: rede de relações pessoais estreita, fofoca e necessidade de segredo. 
Não obstante as questões acima elencadas, outras duas precisam ser pontuadas. Na minha percepção, elas são centrais para entender a não-migração de alguns sujeitos da pesquisa. Refiro-me a questões que envolvem pobreza e distância. A região de minha pesquisa está distante mais de $400 \mathrm{~km}$ da capital do estado, Campo Grande. Ela está a $235 \mathrm{~km}$ da cidade mais próxima no Brasil, Miranda. Essa realidade, impõe a necessidade de construir mecanismos de autogerir as necessidades, inclusive, no mundo dos afetos, do erotismo e da sexualidade.

A distância somada à questão socioeconômica é um fator a ser considerado para a permanência na região. Corumbá e Ladário não são cidades ricas. Há uma discrepância muito grande e bastante visível entre ricos e pobres, entre aqueles que moram antes dos trilhos do trem, mais próximos do centro da cidade e da região do Porto Geral, e a parcela majoritária da cidade, que mora depois dos trilhos, nos bairros mais pobres e periféricos. A pobreza e a distância ajudam a compor o mosaico de particularidades que fazem a experiência do envelhecimento entre sujeitos com condutas homossexuais na região do Pantanal ser muito específica ${ }^{2}$.

Tendo essas questões pontuadas, esse artigo busca, em um primeiro momento, destacar as mudanças e perspectivas observadas no âmbito da sexualidade, por alguns de meus interlocutores de pesquisa, ao longo do curso da vida, destacando, especialmente, as questões mais flagrantes do processo de envelhecimento. Em um segundo momento, o artigo reflete sobre a forma como se estruturavam os relacionamentos puros no chamado tempo de antigamente, em que os interlocutores tinham condições mais facilitadas por uma conjuntura de época para acessar os homens-homens. Nesse sentido, a intenção é apresentar elementos que permitam vislumbrar as transformações da sexualidade, dos afetos e dos desejos em uma região que apresenta certa particularidade, justamente, por operar em uma lógica de não-migração dos sujeitos com condutas homossexuais para os grandes centros urbanos. Interessa, então, perceber os arranjos desenvolvidos por esses sujeitos, no sentido de particularizar suas experiências, bem como as rupturas e permanências com os elementos já apontados em investigações que problematizam a temática nos contextos metropolitanos do país.

\section{Sexualidade e envelhecimento: mudanças e perspectivas}

A sexualidade na velhice, no final do século XX, começou a ganhar maior destaque, talvez, em virtude do aumento da expectativa de vida da população em diversos países do mundo, bem como do interesse na criação de um mercado de bens e serviços empenhado em transformar o envelhecimento numa experiência mais gratificante. Tal fato, igualmente, teve lugar no Brasil onde a visibilidade das pessoas mais velhas é uma crescente. Sendo assim, saberes começaram a ser mobilizados para olhar com maior atenção para os desejos e o erotismo neste momento da vida.

2 No que diz respeito às origens socioeconômicas, uso de forma livre as categorias "camadas médias" e “camadas populares". Para os limites do meu campo, uso "camadas médias" e "médias altas" para pessoas que conseguiram, por meio da escolarização, herança e rendas, produzir algum tipo de ascensão social. Já a expressão "camadas populares" é utilizada para as pessoas com pouca ou nenhuma escolarização e que viviam de empregos informais e temporários ou, quando aposentados, faziam jus ao menor benefício concedido pelo Governo Federal. 
Como apontam Guita Debert e Mauro Brigeiro (2013), a ideia de "envelhecimento ativo" é o modelo mais em voga quando se trata de gestão do envelhecimento no mundo atual. Diante dessa tentativa da Gerontologia de positivação desse momento da vida, a sexualidade se encontra em um lugar central. Manter uma sexualidade ativa ao vivenciar instantes mais avançados do curso da vida representaria, de forma indelével, a vitória de um "envelhecimento ativo".

Essa tentativa da Gerontologia contemporânea faz frente a uma perspectiva que encararia a velhice e o próprio processo de envelhecimento como momentos em que se viveria uma "maturidade pós-sexual" (Debert, Brigeiro, 2012), em que a sexualidade deveria ser deserotizada e desgenenitalizada (Katz e Marshall, 2003). As mudanças diante dessa Gerontologia mais tradicional é que levaram à inclusão e à defesa da sexualidade no curso da vida, especialmente, na velhice.

Ricardo Iacub (2002), por exemplo, diz que o erotismo na velhice é recoberto ora por um silêncio, ora por um discurso que o oculta, ainda que percebendo a sua existência. É como se a vida fosse sendo deserotizada à medida que as pessoas fossem ficando velhas. Neste processo, o prazer sensual transformar-se-ia em ternura e carinho.

No entanto, do ponto de vista de uma “pós-gerontologia”, isto é, por meio de uma problematização da Gerontologia desde a leitura pós-moderna e pósestruturalista (Iacub, 2011), estão sendo realizados diversos estudos políticos, culturais e éticos sobre o envelhecimento que funcionam como marcos para pensar, inclusive, sobre o erotismo e a sexualidade nesse momento da vida.

Por isso, tal como Mike Featherstone (1998), talvez seja profícuo pensar o erotismo na velhice, como vem sendo feito pela pós-gerontologia, como uma infinita variedade de formas baseadas em uma constante invenção, elaboração, domesticação e regulação do impulso sexual, prolongando as possibilidades de uma sexualidade ativa em momentos mais avançados da vida.

Entretanto, esse cenário efusivo presente na Gerontologia contemporânea, parece ser percebido de maneira um pouco diferente pelos meus interlocutores. Eles, de maneira geral, apresentam o momento presente, em que são sujeitos mais velhos, como um tempo de maior calmaria. Isso ocorre, se é possível fazer uma generalização, basicamente, a partir de duas frentes: por um lado, porque há uma limitação física que impede o ritmo de badalação próprio de tempos passados; por outro, a permanente proximidade com a família de origem que, às vezes, envolve, neste momento da vida, inclusive, o retorno à coabitação. Esses fatos fariam com que os interlocutores se afastassem das práticas sexuais e adotassem uma postura mais caseira e, quem sabe, resignada também em função dos contextos de doença que passariam a ser comuns para alguns deles.

É necessária uma crítica à ideia de envelhecimento ativo, pois ela é uma proposta da Gerontologia atual que, muitas vezes, não encontra eco entre as pessoas mais velhas e pode tornar-se, inclusive, um discurso bastante opressor para todos aqueles sujeitos que não conseguem desfrutar da sexualidade na velhice. Há de se pensar também a validade universalizante de um modelo como esse que pode ser ineficiente diante da multiplicidade de contextos em que estão os sujeitos olhados por diferentes investigações. 
Barbosa (78 anos) ${ }^{3}$, por exemplo, diz que a vida do passado acabou. A diferença do passado em relação ao presente seria marcada, entre outros fatores, pelo fato de no passado chover bofe. Barbosa é um exemplo de como as duas perspectivas podem aproximar-se, isto é, considera-se sossegado em relação à sexualidade em vista de estar mais velho, ao mesmo tempo em que reside próximo aos parentes e tem um cotidiano marcado por enfermidades que exigem dele não apenas uma rotina de cuidados, mas visitas frequentes ao hospital, o que consome boa parte de seu tempo. E talvez também signifiquem a ausência de uma vida sexual, do prazer sexual.

Esse tempo de mudanças é percebido na vida de Luma (57 anos)4. Luma diz que o meu apetite sexual, de uns cinco anos pra cá, diminuiu muito. Muito, muito, muito mesmo. Ela diz que não tem mais a mesma necessidade sexual que tinha anos atrás, quase como uma compulsão. Se aparece, bem. Se não aparece, bem também:

\begin{abstract}
eu nunca me preocupei. É uma coisa assim que não está me fazendo falta. Porque se tivesse me fazendo falta, eu teria procurado um médico. Mas pra mim é bem bom, porque pelo menos eu não gasto. Porque na idade que eu estou, se eu arrumo um garoto, ele não vai vir aqui por causa dos meus belos olhos. Ele vem porque ele quer dinheiro. Não vem porque ele me quer, porque ele está a fim (Luma, 57 anos).
\end{abstract}

Um fato curioso trazido por Luma é o de perceber as trocas eróticas e sexuais mediante ganhos financeiros para os parceiros com os quais eventualmente se relacionaria. Segundo a interlocutora, a razão que levaria um homem a se interessar por ela, uma bicha velha, não remontaria aos seus belos olhos. Deveria, pois, existir um atrativo a mais. Esse atrativo seria o dinheiro. Aqui, Luma corrobora a ideia clássica, presente inclusive em alguns trabalhos (Paiva, 2009, Mota 2011, Pocahy 2012, Duarte 2013), sobre as relações intergeracionais. À pessoa mais velha caberia oferecer algum tipo de vantagem para o homem mais novo se envolver com ela.

O paradigma tradicional da moderna Gerontologia via a velhice e o processo de envelhecimento como um momento de derrocada da vida e, consequentemente, como a preparação para o final, isto é, a morte. Assim, as doenças impediriam uma vida sexual ativa na velhice ou a vivência de um erotismo mais frequente. Contra esta perspectiva fatalista, então, houve todo um investimento de valorar os momentos avançados da existência mediante uma série de inciativas, o que ficou conhecido, segundo Ricardo Iacub (2011), como pós-gerontologia, ou Gerontologia pós-moderna. Nessa época, então, poderiam ser desenvolvidas estratégias que ensejassem novas performances eróticas e sexuais que não determinariam o exclusivo abandono da dimensão erótica e sexual da vida (Featherstone, 1998; Debert, 1999; Brigeiro, 2000; Simões, 2004).

Talvez uma das conversas mais esclarecedoras sobre a sexualidade nesse momento da vida, quando os interlocutores já estão mais velhos, eu tenha tido com Mauro (67 anos)5. O trecho a seguir sintetiza sua visão sobre a sexualidade:

3 Barbosa é negro, tem 78 anos, vive na periferia de Corumbá. Pertence às camadas populares. É magro, de estatura mediana. É aposentado e apresenta um quadro clínico composto por várias enfermidades.

4 Luma é branca, tem 57 anos e vive na periferia de Corumbá. Pertence às camadas populares. Luma é alta, gorda, com cabelos curtos e tingidos de louro. Hoje se apresenta socialmente como homem, mas já se "montou" durante muito tempo.

5 Mauro é branco, tem 67 anos, alto e pertence às camadas médias. O interlocutor nasceu em Ladário, mas, quando jovem, a família se mudou para Corumbá. 


\begin{abstract}
Eu tenho os mesmos desejos, a minha cabeça voa. Eu continuo muito sexual, na cabeça, porque o corpo já dá sinais de que as coisas não andam no mesmo ritmo. Por isso que te digo, minha vida é mais tranquila. Virei caseiro, coisa que eu nunca fazia até uns anos atrás. Estava sempre na rua, de segunda a segunda. Ia atrás dos garotos, conseguia e tinha sexo quase sempre. Vivia para conquistar os garotos. Me perdendo em muitos braços que nunca conseguiram ou que nunca quiseram ficar por muito tempo comigo. Mas isso também me deixava louco de vontade: saber que a coisa era difícil e que depois da conquista ia durar bem pouco. Esta busca acho que me animava e me fazia viver (Mauro, 67 anos).
\end{abstract}

O interlocutor é muito didático, inclusive quando aponta o teor das mudanças: trata-se de um "esgotamento" do corpo, mas não de uma falência da cabeça. Quer dizer, os desejos persistem, mas, muitas vezes, o corpo não obedece. Isso o obriga a novas dinâmicas que envolvem uma redescoberta do mundo da casa e a busca por uma, ainda indesejada, impertinente, tranquilidade.

Os trabalhos de Ricardo Iacub (2011), Julio Simões (2004), Mike Featherstone (1998), Mauro Brigeiro (2000) e Jeffrey Weeks (1983) mostram uma queixa quase comum: certo sentimento de desorientação diante do mundo dos desejos, do erótico e das práticas sexuais a partir de um momento $\mathrm{X}$ da vida, em que os sujeitos começam a se sentir mais velhos. Este tempo, o do sentir-se mais velho, não é um momento tácito, demarcado sobre determinados lindes etários, portanto, apresenta-se de maneira completamente fluida e acomete a cada sujeito, geralmente, em tempos particulares.

Iacub (2011) fala, por exemplo, em um mundo da sexualidade muito orientado para a juventude, para a pujança dos corpos jovens e para a beleza destes mesmos corpos. Simões (2004) ainda documenta o trânsito dos coroas pela cena GLS, ostentando alguns signos de prestígio desta meia idade, como estabilidade financeira e uma vida saudável, mas, a todo instante, tensionada justamente com o ser mais velho diante de seus potenciais parceiros.

Em Brigeiro (2000), aparecem as doenças como fatores que limitariam esse trânsito dos sujeitos, não apenas no mundo dos desejos e das trocas eróticas e sexuais, mas mesmo no espaço público, em que a paquera e a sacanagem poderiam ocorrer de forma mais ostensiva. Isto vai ao encontro da lenta perda das competências, assinalada por Featherstone (1998), pois elas retirariam do sujeito a capacidade de se sentir pleno, uma vez despossuído de alguns atributos físicos, cognitivos ou emocionais.

É interessante o trabalho de Weeks (1983), no contexto inglês, ao mostrar como existem formas diversas de estabelecer o curso da própria vida, como as identidades são consolidadas a partir de múltiplas influências, como os comportamentos sexuais são historicamente orientados e, portanto, como tudo isso está em constante transformação. Sendo assim, uma ideia de vida plena, inclusive do ponto de vista da sexualidade, não deveria ter fim na velhice, mas como ocorreria com o próprio curso da vida - diante deste novo momento, ela deveria se reinventar.

Santiago (61 anos $)^{6}$ conta que ainda mantêm sua sexualidade em dia, mas que hoje ela ocupa um lugar bem diferente em sua vida. Ele chega a falar que a sexualidade, depois de um tempo, passou a ficar quase que em segundo plano.

Eu lembro que antigamente, se eu ficasse três dias sem fazer sexo, eu ficava com dor de cabeça. Ficava desesperado. E hoje se eu fico uma semana, se passo uma semana ocupadíssimo, ela passa. Eu fico hoje uma semana, dez dias sem o sexo. Mas há uns anos atrás, da onde. Três dias pra mim já era o máximo que eu aguentava. Ficava desesperado. Mas aí você vai suprimindo, hoje é jantarzinho com amigos. Uns anos

6 Santiago tem 61 anos, é pardo, baixo e pertence às camadas médias. 
Santiago mostra a dinâmica de sua vida com as mudanças que podem ser operadas ao longo do curso da vida no que diz respeito à sexualidade. Para tanto, utiliza, como elemento que se sobrepõe à prática sexual mais recorrente, as inúmeras atividades sociais e laborais com as quais passou a se envolver. Segundo conta, foram várias as ocasiões em que desmarcou reuniões para se encontrar com seus bofes. Porque estar com eles era de suma importância para sua satisfação pessoal.

O interlocutor conta, por meio desse exemplo, que a centralidade da sexualidade foi sendo suprimida em nome de outras situações que, igualmente, dão-lhe bastante prazer: como encontros com amigos e as atividades sociais referentes ao seu trabalho que lhe permitem um trânsito entre pessoas muito diferentes. Ademais, refere-se a essa nova dinâmica de sua vida como resultado de uma fase de maior tranquilidade, pois já teria aprontado muito na cidade e fora dela.

Além disso, diz entre sorrisos: quando passa dos sessenta, meu amigo, tem que dar uma acalmada mesmo. Mesmo assim, refuta de maneira peremptória a pecha de velho e espera nunca chegar a esta condição, pois pretende usar todas as possibilidades para se manter na ativa e retardar este processo, ainda que pisando no freio algumas vezes. Pisar no freio, tudo bem. Parar, nunca ${ }^{7}$.

De maneira geral, os interlocutores - ainda que por vias distintas mostram que há um processo de mudança em curso no que diz respeito à sexualidade, especialmente, no presente, em que vivem momentos mais avançados no curso da vida. Em todas as situações apresentadas, a sexualidade dos interlocutores estava em relação direta com os seus bofes, amantes, homens, casos.

Esse cenário meio aterrador, por óbvio, não deve ser pensado de maneira generalizada, porque mesmo entre meus interlocutores há o apontamento de possibilidades de reinvenções das experiências de envelhecimento e velhice, inclusive do ponto de vista da sexualidade e do erotismo. Sobretudo entre os que não se sentem velhos, há uma série de estratégias para permanecer na ativa da paquera, ainda que trabalhando em um ritmo mais lento.

\section{O "tempo de antigamente": "relacionamentos puros" e "homens-homens"}

Interlocutores das diferentes redes fazem demoradas menções aos homens, marcando, já na fala, uma fronteira: nós, as bichas; eles, os homens. Em conversas individuais que mantive, em rodas de conversas em festas e bares, ou mesmo nas entrevistas gravadas, a referência aos amantes foi uma constante. Dentre os inúmeros amantes que circularam pela vida movimentada dos meus interlocutores, a recorrência nas referências remonta aos marinheiros. Os

\footnotetext{
7 Alguns trabalhos realizados no Brasil são significativos ao mostrar a ocupação das pessoas de mais idade neste novo momento do curso da vida. Entre estes trabalhos, destaco alguns: os programas para a "terceira idade", especialmente, para mulheres, promovidos, entre outros, pelo Serviço Social do Comércio, desde os anos de 1960 (Debert, 1999; Alves, 1999); os bailes da "terceira idade" onde reúnem-se casais mais velhos (Alves, 2004); o movimento dos aposentados, transformando esta categoria em um agente político importante, notadamente, o público masculino (Simões, 20oo); ou mesmo a sociabilidade em praças e outros espaços, como shopping centers, por exemplo (Brigeiro, 200o).
} 
marinheiros, genericamente, povoam o imaginário da minha pesquisa como amantes ideais, homens de verdade, bofes.

Simone $(67 \text { anos })^{8}$ é das únicas interlocutoras que disse preferir os soldados e até hoje não resiste a um cheiro de farda. Ela conta que os marinheiros não eram bem vistos na cidade, pois as famílias entendiam que eles eram bagunceiros e estavam de passagem pela região, ou seja, não era próprio deles construir uma vida no lugar: vinham de fora pra servir aqui. Assim me conta:

\begin{abstract}
Sabe, a minha paixão era soldado. Teve uma época que vinham soldados de Paranaíba, Três Lagoas, só caras bonitos. Aqui eles não tinham parentes, não tinham nada. Aí, chegava na sexta-feira de tarde, meu bem, - eu morava lá em Corumbá - na minha casa aparecia aquela fila de soldado. Aí eles iam pra casa, às vezes, estavam final de semana de folga. Saíam só segunda-feira de manhã. Ou no domingo à noite (Simone, 67 anos).
\end{abstract}

Se o marinheiro aparecia como uma figura de prestígio diante das bichas, talvez o mesmo não ocorresse diante das ditas boas famílias da cidade. Nessas, a figura dos marinheiros era vista com restrições, quando não, com desprezo. A explicação de alguns interlocutores para a proximidade entre bichas e marinheiros não é apenas do âmbito erótico e sexual, mas de algo que se assemelha a uma rede de suporte afetivo (e material) do qual esses sujeitos se viam afastados ao chegar ao Pantanal.

Como afirma Mauro (67 anos), os marinheiros gostavam e gostam muito dessa safadeza toda. O interlocutor diz ter vivido alguns casos com marinheiros. Segundo ele, nada muito duradouro ou sério, pois não via muita graça em marinheiro. Mauro os achava muito limpos, muito organizados. No entanto, nunca dispensou quando aconteceu. A preferência do interlocutor seria por homens mais rústicos, gente mais largada, um pouco suja.

Tom (53 anos) ${ }^{9}$ afirma que conseguir homens nunca foi um problema. Suas estratégias de conquista passavam pelo uso desmedido de seu poder de persuasão. Tom diz que a conquista era uma consequência quase natural de seu poder, sua lindeza, sua boniteza, seu cabelo, sua pele, sua cútis. Ele acionava esse conjunto de elementos que o capacitavam a interagir lascivamente com potenciais parceiros nos espaços de sociabilidade pelos quais transitava na cidade.

Um detalhe que produziu eco em vários momentos do meu trabalho de campo, presente em conversas informais e entrevistas, é o fato de que os interlocutores, diante de seus amantes, performatizavam, como bichas. Por outro lado, os amantes seriam o os machos, os homens. Algumas bichas dos homens poderiam expressar publicamente algum grau de masculinidade viril capaz de as confundir com certo padrão esperado de homens com conduta heterossexual. Essa performance era apenas para espaços públicos. No âmbito do privado, o bichar se tornava um elemento que marcava a distância entre uns e outros ${ }^{10}$.

8 Simone tinha 67 anos, se considerava um homem gay, mas preferia ser chamada pelo nome social dos tempos em que se montava. Simone faleceu em 2014. Ela era negra, de cabelos compridos e grisalhos, magra e caminhava com muita dificuldade. Simone era pobre e vivia na periferia de Ladário.

9 Tom tem 53 anos, é branco, de estatura baixa, magro, com cabelos tingidos. É funcionário público e tem ensino superior. Reside em um bairro da periferia da cidade.

10 Sobre bichar, há um caso exemplar no livro Consumindo lugares, Consumindo nos lugares, de Isadora Lins França (2012). No livro de França, o bichar aparece como uma categoria acionada por alguns frequentadores do Samba GLS. Ele reflete um dos mecanismos de defesa construídos pelo processo de agenciamento do sujeito. O bichar é utilizado para afirmar uma identidade e construir respeito sobre si. O bichar se desdobra no bater cabelo em espaços hetero para chamar a atenção de algum pretendente e se anunciar como "homossexual". Em meu campo, por outro lado, o bichar aparece como expressão de sinais diacríticos de conduta homossexual entre os pares em locais privados. 
Há, nessas performances, uma referência clara aos modelos classificatórios propostos por Peter Fry (1982). As distâncias entre bichas e homens precisavam ser marcadas e em outros instantes começavam a ser borradas, como sintomas dos processos de mudanças que tomavam a sociedade brasileira. Os instantes íntimos de descontração, na esteira da hierarquia bicha/homem, foram destacados por James Green (2000), nas festas das bonecas no Rio de Janeiro, ou mesmo por Thiago Soliva (2012), nos primórdios da Turma Ok, entre concursos diversos e montagens e desmontagens.

Tal situação também já estava presente na investigação de Barbosa da Silva (2005), na São Paulo dos anos de 1950, nas reuniões em que os homossexuais ostensivos vestiam-se de mulher, por exemplo. E eu mesmo percebera isso entre meus interlocutores da pesquisa que realizei em Santa Maria-RS (Passamani, 2011). Para um espaço público, era perseguida uma postura que fosse capaz de confundir os sujeitos com homens com conduta heterossexual.

Assim, seja nas festas, nas farras e nos fervos, ou em outros espaços de conquista e sedução, havia uma espécie de marcação de diferença, quase hierárquica, que separava bichas, passivas, de homens, bofes e ativos. A esse respeito, Teo (77 anos) ${ }^{11}$ é bastante claro quanto aos casos estabelecidos:

Eu me sentia mulher na cama. Os homens nunca reclamaram. Eu fazia e fazia eles felizes. Nunca fui ativo e eles não reclamavam. Era mais difícil, né? Porque era homem, homem. Agora que é que tá assim. Os homens andam dando mais que as bichas (Teo,77 anos).

Teo define que o encontro sexual entre dois homens precisava ser mediado por alguma estratégia que denotasse a hierarquia estabelecida, nos moldes de uma relação heterossexual. A analogia ao encontro de dois homens era a relação homem/mulher. Em vista disso é que, já em nossos primeiros encontros em sua casa, quando eu lhe pedia mais detalhes sobre o que ele me contava, o interlocutor dizia que ele, como bicha, deveria comportar-se na cama, semelhante ao "tipo ideal" da performance de uma mulher ${ }^{12}$.

O que perpassava a ideia dos meus interlocutores é que no tempo de antigamente, as relações se estabeleciam entre uma bicha e um homem. Eles entendiam que não era possível a formação de casais de bichas, pois haveria, na visão deles, papeis determinados para umas e para outros. Não poderia uma bicha comer outra bicha. Em pesquisa realizada a partir do trânsitos de homens homossexuais de São Paulo e Recife, Isadora Lins França (2013) ouviu na capital pernambucana a expressão "frango com frango é negócio de paulista". Esta expressão alude a certa igualdade nas relações entre os "paulistas" que era impensada nos cenários recifenses em que a ordem parecia determinar o encontro hierárquico entre frangos (a variante local da bicha) e cafuçus (os homens másculos e, de preferência, heterossexuais). No meu campo, como parece ter ocorrido no de França, o ato de comer alguém, segundo contam, eles entendiam que era reservado para os homens heteros. Estes homens tinham suas namoradas, seus casamentos, mas se aventuravam com as bichas. Luma (57 anos), assim relembra:

11 Teo tem 77 anos, é pardo, de estatura mediana, um pouco gordo. Pertence às camadas médias, é funcionário público aposentado. Caminhava com dificuldades e entre as complicações da saúde, está um diabetes.

12 Sobre o modelo hierárquico de classificação da sexualidade, notadamente a hierarquia bicha/homem, ver Fry (1982). Um olhar interessante sobre a análise de Fry foi feito por Carrara e Simões (2007). 
Você não consegue um relacionamento puro. Porque naquele meu tempo a gente ainda tinha muito relacionamento com hetero. Hoje em dia você não acha mais. $E$ mais gay com gay. $E$ isso não entra na minha cabeça. Um gay junto com outro gay. Não, não, não. Prefiro ficar o resto da vida sozinha. Olha, [...] eu gosto de me sentir, quando tenho relacionamento, a parte feminina e ele, logicamente, o marido, poderia se dizer. Não me importa se tenha uma namorada. Prefiro que tenha uma namorada. Namorada por mim não é problema ter (Luma, 57 anos).

A fala de Luma é muito interessante. Ela qualifica os encontros entre uma bicha e um homem como a possibilidade do começo de um relacionamento puro. Luma ainda dá pistas de que houve ou está em curso uma mudança no estabelecimento destes vínculos, hoje é difícil achar homens com conduta heterossexual dispostos a se relacionar com as bichas. Isto teria obrigado o começo de relações que ela chama de gay com gay. Isto sim, as relações gay com gay, algo imponderável em sua compreensão, ao ponto de preferir ficar o resto da vida sozinha a se aventurar com um gay.

Os marinheiros eram os homens mais desejados pelas bichas pois representavam um estereótipo diferente de masculinidade viril e hegemônica (Kimmel, 1998) diante das pessoas da região. Além disso, ainda que se relacionassem com as bichas, a imagem de heteros não era questionada. Os marinheiros eram vistos como estrangeiros no Pantanal, algo que agregava valor em um suposto e fluído mercado do erotismo local. As características que adensavam o valor dos marinheiros se deviam ao fato de que eles eram mais altos, mais fortes e mais brancos. Conquistar um marinheiro era razão de prestígio diante dos demais.

Mauro (67 anos) corrobora a visão da relação bicha-homem:

\begin{abstract}
Sou de um tempo que não tinha esse negócio de gay amigar com gay. Os gays, a gente, buscavam homens heteros para fazer sexo. Eu imaginava que quem namorava e casava eram os heteros. Gays deveriam viver de sexo. Eu ficava confuso com isso. Eu não tinha referência. Tinha uma ou outra bicha na cidade. Parecia que o mundo era hetero e eu era gay. Tempos depois é que apareceram gays na minha turma de amigos. Preferiam que a gente fosse drogado e sei lá mais o que, do que ser homossexual. A gente era tudo, inclusive homossexual (Mauro, 67 anos).
\end{abstract}

O interlocutor dizia que não conseguia, em sua juventude, entender o fato de duas pessoas com conduta homossexual, nomeadas por ele como gays, poderem se relacionar. Mais do que a impossibilidade sexual promovida por duas pessoas, em tese, passivas, o que estava em questão naquele tempo, segundo o interlocutor, era a impossibilidade do afeto.

$\mathrm{O}$ afeto seria reservado para os casais com conduta heterossexual. Não haveria lugar no roteiro dos afetos para aqueles gays que amigavam com outros gays. Aliás, amigar é uma expressão que apareceu com recorrência no campo, especialmente, entre os interlocutores mais velhos. Este termo seria um marcador geracional. Com o amigar, eles representam as relações estabelecidas entre duas pessoas com conduta homossexual.

Essa mesma lógica parece funcionar para as relações vividas por Simone (67 anos). Ela dizia nunca ter gostado de amigar com gay. Entre as questões postas pela interlocutora, está o fato de o homem com conduta homossexual possuir trejeitos. Simone dizia que basta o homem virar a mão pra mim que ela perdia qualquer tipo de interesse ${ }^{13}$. Em vista disso é que afirma ter procurado, 
ao longo da vida, relacionar-se com homem mesmo. O verbo namorar, no meu campo, aparece referente a relações entre pessoas com conduta heterossexual. $\mathrm{O}$ que as pessoas com conduta homossexual viviam tinha uma série de nomes como casos, relação, viver, mas quase nunca se tratava de um namoro.

A razão apontada para este lugar de passividade das bichas, segundo Santiago (61 anos), está nos relacionamentos dos heteros. Para ele, no tempo antigo (décadas de 50 e 60), as meninas não davam para seus namorados, ou seja, não havia entre estes casais a consumação do ato sexual. Estes casais não passavam das preliminares. Logo, o homem ficava subindo pelas paredes. A solução encontrada era comer uma bicha para não explodir de tesão.

À medida que as meninas foram ficando mais sem-vergonha, começaram a dar para os namorados, logo, começou a faltar, no mercado sexual da cidade, aqueles que comessem as bichas. Desse modo, elas (as bichas) tiveram que estabelecer novas estratégias de relação, resultando em um modelo mais igualitário, passando a se relacionar entre si. Santiago (61 anos) explica assim:

\begin{abstract}
A coisa muda quando as meninadas foram ficando sem-vergonha. Porque elas não davam e os caras tinham que comer alguém. E saíam da casa da namorada [...] e iam comer o viado. Tinha gay que ficava esperando às voltas da casa, às dez horas, porque sabia que ele ia escorregar, esfregar, amassar a namoradinha, pegar no peito, isso e aquilo, mas não ia comer. Cara vinha em ponto de bala. $O$ primeiro viado que ele achasse na reta, era esse mesmo (Santiago, 61 anos).
\end{abstract}

Teo (77 anos) é dos que se mostra mais incomodado com as mudanças nas relações entre homens e bichas. Segundo ele, antigamente tudo era melhor, sobretudo no que diz respeito às relações sexuais, porque as bichas se relacionavam com homem-homem. O homem-homem aventado por Teo como uma categoria em extinção contrasta com o que ele diz ser o momento atual, em que os homens andam dando mais que as bichas.

É interessante pensar, seguindo Sérgio Carrara (2005a), que a "homossexualidade", mais do que uma dimensão da sexualidade, pode ser vista como um "lugar social" a partir do qual se tem condições de conversar com mudanças mais amplas que tiveram lugar no Brasil ao longo das últimas décadas, sobretudo a partir da ditadura militar iniciada com o golpe de 1964 . Quer dizer, o que os interlocutores estão notando de diferente nas relações entre bichas e homens, na maior visibilidade das bichas, diz respeito a um momento de transformações na sociedade em que possibilita para a "homossexualidade" novos lugares e atesta mudanças sociais inclusive no imaginário e no âmbito da representação desta dimensão da sexualidade.

Portanto, há uma gama de situações que fazem com que, inclusive, a "homossexualidade" seja percebida, vivida, experimentada e retratada a partir de diferentes lugares de representação denotando mudanças sociais. Talvez esse processo ainda esteja em curso, agora sob a ótica da reclamação de direitos negligenciados à população LGBT. Na época de que se recordam meus interlocutores, essas mudanças se davam de forma mais microscópica desde as performances sexuais. A revolução dos costumes fora percebida por eles, primeiramente na cama, mas ela vocalizava mudanças mais amplas de aspectos estruturais da sociedade.

As falas dos interlocutores se encontram na perspectiva de pensar as transformações operadas no que se chama de mundo gay, a partir, segundo 
eles, de mudanças que ocorreram entre os casais com conduta heterossexual. Desde o instante em que o sexo teria começado a fazer parte destas relações, a procura por pessoas com conduta homossexual para encontros sexuais teria arrefecido, razão pela qual os interlocutores começaram a perceber, na região, um rearranjo na formação dos pares sexuais, isto é, começaram a ter maior visibilidade os pares formados por dois gays, duas bichas. O argumento é bastante simples, conforme pontua Luma: faltou homem, as bichas tiveram que começar a se pegar.

Diante deste cenário, os sujeitos criam estratégias de sociabilidade homoerótica nos interstícios ou ao largo de uma "heterossexualidade compulsória" e institucionalizada. O panorama, aparentemente, de quase desolação em vista de ausências visíveis de referência às práticas homossexuais e a este tipo de erotismo, ganhou contornos complexos nas margens da própria margem e propiciou uma rotina e um trânsito intensos no mundo desses desejos para além do dizível, do ordeiro e do possível. O que estaria posto era a necessidade construir e habitar impossíveis, tornados possíveis todos os dias, bem como as lembranças elencadas pela memória dão pistas das tensões entre subjetividades individuais e coletivas.

\section{Considerações Finais}

Nesse artigo, mostrei como o processo de envelhecimento e a velhice produzem uma tensão entre as dimensões de público e privado. Nos contextos em que eu trabalhei, as vivências da sexualidade, se apresentaram relacionadas com experiências públicas. Isso ficou claro, na rejeição apresentada por alguns interlocutores de permanecerem nos limites da casa, por exemplo, em oposição ao circular e estar na rua. Casa e rua servem, aqui, alegoricamente, para pensar velhice e juventude, respectivamente.

As tentativas de permanecer jovem, administrando a vivência de uma sexualidade com uma intensidade mais moderada, com mais cuidados, está ligada a uma ideia de trânsito e circulação pelo espaço público. Esta noção de público busca se contrapor ao privado, que é representado pelo "estar em casa" em frente à televisão, que seria próprio do "ser velho". Por que chamo a atenção para esta questão? Porque, costumeiramente, a sexualidade é alocada (com exceção do campo da prostituição) na dimensão privado. O meu campo mostra o contrário disso. A sexualidade está no público ${ }^{14}$.

Ao longo do artigo, apresentei experiências, personagens e estratégias que organizam não apenas a dimensão da sexualidade e do erotismo, como as próprias relações sociais mais amplas, assim como um jeito muito particular de viver a vida. Estes momentos passeiam entre os polos opostos de protagonismos e infortúnios. É neste trânsito entre protagonismos e infortúnios que parecem estar sedimentadas as experiências afetivas, eróticas e sexuais dos interlocutores, sobretudo nos momentos mais recentes, quando são notadas as alterações mais flagrantes em direção à velhice, por meio do processo de envelhecimento, pelo menos, do corpo físico.

Assim, na esteira de Ernesto Meccia (2011), parece que a situação apresentada pelos interlocutores nos remete à compreensão de estamos diante da existência de diferentes regimes de visibilidade. Porém, diferente das

14 A sexualidade como parte da dimensão pública também aparece nas pesquisas de Roberto Efrem Filho (2013). Em sua investigação, a exceção se dá entre as chamadas "bichas velhas", aquelas que contratam os "michês" e os levam para casa. Há, portanto, uma intersecção entre geração/envelhecimento com o privado que merece ser destacado. 
pesquisas de Meccia, o que meus interlocutores chamam de tempo de antigamente, e ele de homosexualidad, se apresentam de forma distinta. Os elementos do meu campo não me permitem pensar naquele tempo como o momento da existência de uma comunidade genuinamente sofredora e enclausurada. Havia, como mostrei anteriormente, muita diversão e a transição - como a maioria das transições - não se fez sem alguns impactos e mudanças, algumas vezes, radicais e profundas.

Por conta disso, para os mais velhos, a inconformidade com algo semelhante à "gaycidade", este tempo de "des-diferenciação", no qual reina a bagunça e os homens teriam deixado de ser tão homens assim, acomete-os de forma mais flagrante. Outrossim, foram estes sujeitos de mais idade, justamente, os que viveram, mais intensamente, o tempo da homosexualidad.

Nesse sentido, dei especial atenção para a percepção de como começam a ocorrer alterações no campo da sexualidade, na contramão do que é apregoado por uma Gerontologia que aposta na velhice, ou no envelhecimento, como momentos de novas descobertas para a manutenção e o prolongamento da vida sexual ativa e, consequentemente, de uma nova vivência da sexualidade.

Também é importante destacar, entre as particularidades da experiência da homossexualidade na região do Pantanal, expostas acima, certo desconhecimento do que ocorre fora da região, especialmente entre os mais velhos, cujos trânsitos deixaram de ocorrer em vista das doenças e infortúnios variados. Por outro lado, entre os mais jovens, talvez essa diferença possa ser marcada, inclusive, entre o que muitos poderiam entender como uma deficiência da região, isto é, a falta de uma segmentação do mercado do consumo e do entretenimento para as pessoas com condutas homossexuais na região. Alguns deles, percebem isso como uma vantagem, pois a visibilidade do mercado segmentado seria, na visão desses, um impulsionador para $o$ preconceito e a discriminação. No entanto, esse é um dado que ainda carece análise em reflexões posteriores.

Por derradeiro, procurei mostrar que o teorizado pela Gerontologia não necessariamente se faz presente no cotidiano dos meus interlocutores, que percebem o envelhecimento e a velhice como momentos de maior tranquilidade, exigindo algum retraimento social que acaba por gerar uma menor frequência sexual, quando não sua eliminação. Aliado à passagem dos anos, mostrei como outro aspecto desta dimensão do erotismo e da intimidade também passou por um processo de transformação. Falo especificamente dos amantes. Nesse artigo, a atenção recaiu ao tempo de antigamente e aos homens-homens de seus relacionamentos puros. Nestas ocasiões, as bichas faziam as vezes das mulheres, porque estas se recatavam diante da moral de época. A dádiva trocada, em meio a tantos dons, portanto, dizia respeito ao sexo, ao desejo, ao alcance do gozo mútuo, uma busca de machos e bichas.

\section{Referências Bibliográficas}

ALVES, Marcelo. A gestão da experiência de envelhecer em um programa para a terceira idade: a Unati/Uerj. Textos Envelhecimento, 2 (2): 23-63.1999 
ALVES, Andréa Moraes. A Dama e o Cavalheiro: um estudo antropológico sobre envelhecimento, gênero e sociabilidade. Rio de Janeiro: FGV, 2004.

BRAGA, Gibran T. 'Não sou nem curto'.Prazer e Conflito no Universo do Homoerotismo Virtual. Dissertação (Mestrado em Sociologia e Antropologia). PPGSA UFRJ, 2013.

BRIGEIRO, Mauro. Rir ou chorar? Envelhecimento, sexualidade e sociabilidade masculina. Dissertação (Mestrado em Saúde Coletiva). Instituto de Medicina Social. Rio de Janeiro: UERJ, 2000.

CARRARA, Sérgio. Só os viris e discretos serão amados? Disponível em http://www1.folha.uol.com.br/fsp/mais/fs1906200509.htm. Acesso em 17/05/2014. 2005 .

CARRARA, Sérgio. O Centro Latino Americano em Sexualidade e Direitos Humanos e o 'Lugar' da Homossexualidade. In. GROSSI, Miriam Pillar [et al.](org.). Movimentos sociais, educação e sexualidades. Rio de Janeiro: Garamond. 2005a.

CARRARA, Sérgio e SIMÕES, Júlio Assis. Sexualidade, cultura e política: a trajetória da identidade homossexual masculina na antropologia brasileira. Cadernos PAGU (28), Campinas: Núcleo de Estudos de Gênero PAGU/Unicamp, p. 65-101, 2007.

CORRÊA, Lúcia Salsa; CORRÊA, Valmir Batista. A história do Pantanal contada pelo MUHPAN. São Paulo: Via Impressa Edição de Artes, 2013.

DEBERT, Guita Grin. A construção e reconstrução da velhice: família, classe social e etnicidade. In. NERI, Anita Liberalesso; DEBERT, Guita Grin (orgs.). Velhice e Sociedade. Campinas-SP: Papirus, 1999. p.41-68.

DEBERT, Guita Grin; BRIGEIRO, Mauro. Fronteiras de gênero e a sexualidade na velhice. Revista Brasileira de Ciências Sociais. V.27, p.37-54, 2012

DEBERT, Guita Grin; BRIGEIRO, Mauro. A velhice, o sexo e o erotismo politicamente correto. In. PASSAMANI, Guilherme R. (Org.). (Contra)pontos: ensaios de gênero, sexualidade e diversidade sexual. Cursos da vida e gerações. 1ed.Campo Grande: Editora UFMS, 2013. p. 29-48.

DUARTE, Gustavo de Oliveira. O "Bloco das Irenes". Articulações entre amizade, homossexualidade(s) e o processo de envelhecimento. Tese (Doutorado em Educação). PPGE, UFRGS. Porto Alegre, 2013.

EFREM FILHO, Roberto. Corpos Brutalizados: conflitos e materializações nas mortes de LGBT. SPG15 - Sexualidade e gênero: espaço, corporalidades e relações de poder. $37^{\circ}$ Encontro Anual da ANPOCS. Águas de Lindóia-SP, 2013.

FEATHERSTONE, M. O curso da vida: corpo, cultura e o imaginário no processo de envelhecimento. In: DEBERT, G.G. (org). Antropologia e Velhice. Campinas-SP: IFCH/ UNICAMP, 1998. 
FRANÇA, I. L. Consumindo lugares, consumindo nos lugares: homossexualidade, consumo e subjetividades na cidade de São Paulo. Rio de Janeiro, EDUERJ, 2012.

FRANÇA, I. L. . Frango com frango é coisa de paulista : erotismo, deslocamentos e homossexualidade entre Recife e São Paulo. Sexualidad, Salud y Sociedad (Rio de Janeiro), v. 1, p. 13-39, 2013

FRY, P. Da hierarquia à igualdade: a construção histórica da homossexualidade no Brasil. In: FRY, Peter. Para inglês ver: identidade e política na cultura brasileira. Rio de Janeiro: Zahar, 1982. p. 87-115

GAGNON, John H. Uma interpretação do desejo. Ensaios sobre o estudo da sexualidade. Rio de Janeiro: Garamond, 2006.

GREEN, James Naylor. Além do carnaval: a homossexualidade masculina no Brasil do século XX. São Paulo: EDUNESP, 2000.

IACUB, Ricardo. La posgerontología: hacia un renovado estudio de la gerontología. Revista Latinoamericana de Psicología. V.34, N. 1-2, 2002. p. 155157

IACUB, Ricardo. Erótica y vejez: perspectivas de Occidente. Buenos Aires: Paidós, 2011.

KATZ, Stephen; MARSHALL, Barbara. New sex for old: lifestyle, consumerism, and the ethics of aging well. Journal of Aging Studies, 17 (1): 3-16, 2003.

KIMMEL, Michael S. A produção simultânea de masculinidades hegemônicas e subalternas In. Horizontes Antropológicos/UFRGS. IFCH. Programa de PósGraduação em Antropologia Social. Porto Alegre: PPGAS, 1998.

MECCIA, Ernesto. Los últimos homosexuales. Sociología de la homosexualidad y la gaycidad.Buenos Aires: Gran Aldea Editores, 2011.

MOTA, Murilo. Homossexualidades masculinas e a experiência de envelhecer. Tese (Doutorado em Serviço Social). PPGESS, UFRJ. Rio de Janeiro, 2011.

PAIVA, Crístian. Corpos/Seres que não importam? Sobre homossexuais velhos. In. Revista Bagoas. N.4. CCHL:UFRN, 2009.

PASSAMANI, Guilherme R. Na batida da concha. Sociabilidades juvenis e homossexualidades reservadas no interior do Rio Grande do Sul. Santa MariaRS: EditoraUFSM, 2011.

PERLONGHER, Nestor. O negócio do michê. A prostituição viril. São Paulo: Brasiliense, 1987.

POCAHY, Fernando. Entre vapores \& vídeos pornôs: dissidências homo/eróticas na trama discursiva do envelhecimento masculino. Estudos Feministas, v. 20, n. 2, p. 357-376, 2012. 
SILVA, José Fábio Barbosa da. Homossexualismo em São Paulo: estudo de um grupo minoritário. In. GREEN, James N., TRINDADE, Ronaldo (orgs.). Homossexualismo em São Paulo e outros escritos. São Paulo: EDUNESP, 2005.

SIMÕES, Julio Assis. Entre o lobby e as ruas: movimento de aposentados e politização da aposentadoria. Tese. (Doutorado em Ciências Sociais). IFCHPPGCS. Campinas: Unicamp, 2000.

SIMÕES, Julio Assis. Homossexualidade masculina e curso da vida: pensando idades e identidades sexuais. In. PISCITELLI, Adriana; GREGORI, Maria Filomena; Carrara, Sérgio (orgs.). Sexualidade e saberes: convenções e fronteiras. Rio de Janeiro: Garamond, 2004.

SOLIVA, Thiago Barcelos. A confraria gay: um estudo de sociabilidade, homossexualidade e amizades na Turma OK. Dissertação (Mestrado em Sociologia e Antropologia). PPGSA, UFRJ. Rio de Janeiro, 2012.

WEEKS, Jeffrey. Os Problemas dos Homossexuais Mais Velhos. In.: HART, John; RICHARDSON, Diane (orgs.). Teoria e Prática da Homossexualidade. Zahar Editores: Rio de Janeiro, 1983. 